\title{
AVALIAÇÃO INSTITUCIONAL COMO MECANISMOS DE GESTÃO DEMOCRÁTICA DA ESCOLA PÚBLICA: REFLEXÕES A PARTIR DO ESTÁGIO SUPERVISIONADO - GESTÃO NO INSTITUTO FEDERAL DE EDUCAÇÃO, CIÊNCIA E TECNOLOGIA CATARINENSE
}

\author{
Paula de Souza; Sara Wisenteiner; Filomena Lucia Gossler Rodrigues Silva \\ Instituto Federal Catarinense - Campus Camboriú \\ DOI: 10.15628/rbept.2019.7522
}

Artigo submetido em set/2018 e aceito em ago/2019

\begin{abstract}
RESUMO
Este texto apresenta reflexões acerca de uma experiência de Estágio SupervisionadoGestão realizada por acadêmicas do curso de licenciatura em Pedagogia do Instituto Federal de Educação, Ciência e Tecnologia Catarinense - Campus Camboriú. O referido estágio teve como temática de intervenção a elaboração de uma proposta de avaliação institucional que pudesse ser tomada como mecanismo de gestão democrática da escola pública.
\end{abstract}

Palavras-Chave: Gestão Escolar. Estágio Supervisionado. Avaliação Institucional.

\section{INSTITUTIONAL EVALUATION AS MECHANISMS OF DEMOCRATIC MANAGEMENT OF THE PUBLIC SCHOOL: REFLECTIONS OF THE SUPERVISED-MANAGEMENT PRACTICE AT THE CATARINENSE'S FEDERAL INSTITUTE OF EDUCATION, SCIENCE AND TECHNOLOGY}

\begin{abstract}
This text presents reflections about a Supervised-Management practice carried out by undergraduate students in Pedagogy at the Catarinense's Federal Institute of Education, Science and Technology - Camboriú Campus. This practice had as the subject matter of intervention the elaboration of a proposal of institutional evaluation that could be taken as a mechanism of democratic management of the public school.
\end{abstract}

Keywords: School Management. Internship in Management. Institutional Evaluati. 


\section{INTRODUÇÃO}

De acordo com a Resolução do CNE/CP № 1, de 15 de maio de 2016, que Institui as Diretrizes Curriculares Nacionais para o Curso de Graduação em Pedagogia, licenciatura, o curso de Pedagogia destina-se à formação de profissionais para exercer funções de docência na Educação Infantil e nos Anos Iniciais do Ensino Fundamental; nos cursos de Ensino Médio, na modalidade Normal; de Educação Profissional, na área de serviços e apoio escolar; e em outras áreas nas quais sejam previstos conhecimentos pedagógicos. Além disso, a referida resolução estabelece que o egresso deste curso deverá estar apto para realizar as seguintes atribuições que envolvem o campo da Gestão: participar da gestão das instituições, contribuindo para elaboração, implementação, coordenação, acompanhamento e avaliação do projeto pedagógico e planejando, executando, acompanhando e avaliando projetos e programas educacionais, em ambientes escolares e não-escolares.

O curso de Licenciatura em Pedagogia oferecido no IFC-Campus Camboriú, instituição à qual a experiência em análise se vincula, tem em sua matriz curricular quatro estágios supervisionados, sendo eles: Estágio Supervisionado - Educação Infantil - 5ำ período; Estágio Supervisionado Anos Iniciais do Ensino Fundamental - 6o período; Estágio Supervisionado Modalidades da Educação Básica; 7ํㅜ período e Estágio Supervisionado Gestão - 8o período. Este artigo tem como propósito sistematizar a experiência vivenciada durante o Estágio Supervisionado - Gestão, realizado na Escola de Educação Básica João Goulart, situada no município de Balneário Camboriú. $O$ referido estágio possui as seguintes etapas: a) reflexões teóricas acerca do Estágio em Gestão; b) inserção no campo de estágio; c) elaboração do projeto de intervenção; d) intervenção no campo de estágio; e) reflexões acerca da experiência do Estágio em Gestão.

A temática de intervenção elegida pela escola consistiu na reflexão acerca da importância da avaliação institucional como instrumento e mecanismo para a implementação de uma gestão escolar democrática e na elaboração de instrumentos de avaliação institucional como subsídio para discussão na escola. Para a reflexão sobre gestão escolar e a avaliação institucional, nas reflexões sobre essa experiência, tomamos como referência Paro (2012), Sousa (1999) e Souza (2009).

Em termos metodológicos, este trabalho fundamenta-se em uma abordagem de pesquisa-ação que, segundo Thiollent (apud GERHARDT; SILVEIRA. 2009, p. 40),

[...] é um tipo de investigação social com base empírica que é concebida e realizada em estreita associação com uma ação ou com a resolução de um problema coletivo no qual os pesquisadores e os participantes representativos da situação ou do problema estão envolvidos de modo cooperativo ou participativo. 
Portanto, pode-se dizer que é pesquisa-ação conforme Fonseca (apud GERHARDT; SILVEIRA, 2009), a pesquisa que conta com uma participação intencional do pesquisador no espaço pesquisado. Há, também, escolhas metodológicas que caracterizam a intervenção social do pesquisador na realidade:

\begin{abstract}
O objeto da pesquisa-ação é uma situação social situada em conjunto e não um conjunto de variáveis isoladas que se poderiam analisar independentemente do resto. Os dados recolhidos no decurso do trabalho não têm valor significativo em si, interessando enquanto elementos de um processo de mudança social. $O$ investigador abandona o papel de observador em proveito de uma atitude participativa e de uma relação sujeito a sujeito com os outros parceiros. O pesquisador quando participa na ação traz consigo uma série de conhecimentos que serão o substrato para a realização da sua análise reflexiva sobre a realidade e os elementos que a integram. A reflexão sobre a prática implica em modificações no conhecimento do pesquisador.
\end{abstract}

A pesquisa-ação exige uma imersão no contexto em que a problemática se insere. Há a necessidade, portanto, de contato direto com o objeto investigado, permitindo analisar de forma crítica e reflexiva os problemas encontrados durante tal inserção. Essa metodologia pode oportunizar vivências que contribuam com a transformação da realidade observada, uma vez que abre espaço para que o pesquisador perceba situações que não são identificadas pelos sujeitos já familiarizados com aquela situação/realidade.

Para atender os propósitos deste trabalho, realizamos uma revisão de literatura, considerada etapa fundamental em qualquer investigação. Segundo Gerhardt e Silveira (2009, p. 67) é importante "expor resumidamente as principais ideias já discutidas por outros autores que trataram do problema [...]". As fontes bibliográficas mais utilizadas no trabalho foram livros, teses e dissertações, periódicos científicos e anais de eventos, cujos temas centrais versaram sobre a temática aqui em análise.

Além disso, visando contextualizar o campo empírico, esse é apresentado com base na análise documental realizada a partir de documentos institucionais, entre os quais destacamos o Projeto Político Pedagógico (PPP) e o Plano de Gestão (PG) da Escola de Educação Básica Presidente João Goulart. Novamente, a escolha metodológica considerou 0 que dizem Gerhardt e Silveira (2009, p. 69), para quem a pequisa documental:

É aquela realizada a partir de documentos, contemporâneos ou retrospectivos, considerados cientificamente autênticos (nãofraudados); tem sido largamente utilizada nas ciências sociais, na investigação histórica, a fim de descrever/comparar fatos sociais, estabelecendo suas características ou tendências. Nesse tipo de 
coleta de dados, os documentos são tipificados em dois grupos principais: fontes de primeira mão e fontes de segunda mão.

A partir da pesquisa bibliográfica e documental e dos dados coletados junto à equipe gestora da E.E.B João Goulart, buscamos dialogar com a perspectiva democrática da gestão da escola pública, visando contribuir com reflexões acerca da avaliação institucional como um mecanismo importante de gestão.

Considerado o exposto, organizamos o texto a partir da seguinte estrutura: uma reflexão acerca da administração escolar comprometida com a transformação social; a caracterização da escola em que foi realizado o estágio; uma reflexão sobre Avaliação Institucional como mecanismo e instrumento para favorecer a gestão democrática da escola e, por fim, algumas considerações acerca da experiência vivenciada, apontando para os desafios que percebemos nesse campo da atuação do pedagogo.

\section{REFLEXÕES ACERCA DA ADMINISTRAÇÃO ESCOLAR}

De acordo com Paro (2012), existem pelos menos cinco pressupostos básicos para uma administração comprometida com a transformação escolar. São eles: especificidade da transformação escolar, racionalidade social ou externa, racionalidade interna, caráter mediador da administração e ideias sobre administração escolar e consideração das condições concretas.

O primeiro pressuposto refere-se à especificidade da administração escolar que, de acordo com o autor, diverge da administração empresarial, uma vez que "visa precisamente a servir de instrumento de superação da dominação e da exploração vigentes na sociedade" (PARO, 2012, p. 198). Pensar numa educação comprometida com a transformação social implica compreender que a administração escolar possui especificidades e seus princípios devem estar atrelados à formação integral e à emancipação dos estudantes, ultrapassando a lógica capitalista de uma formação precária para o mercado de trabalho.

Uma formação comprometida com a transformação social deve possibilitar ao estudante condições para fazer a leitura de realidade. Esta, por sua vez, possibilita-Ihe elementos para perceber a importância da consciência crítica, reflexiva e das atitudes democráticas nos processos decisórios.

No segundo pressuposto, Paro (2012) aborda a racionalidade social ou externa. Tal perspectiva nos permite entender que a gestão da escola é realizada considerando legislações e diretrizes que são pré-determinadas pelos sistemas de ensino. No entanto, ao implantá-las, é preciso considerar as necessidades e especificidades da comunidade que atende, ou seja, comprometendo-se com ela. Daí surge o terceiro pressuposto, a racionalidade interna que, segundo o autor, visa a utilização racional dos recursos para que a escola, a partir dos condicionantes externos, possa dialogar com suas especificidades, visando alcançar seus objetivos. 
No quarto pressuposto, Paro (2012) chama a atenção para o caráter mediador da administração, ressaltando quão importante seria se todas as ações fossem realizadas de forma coletiva. $O$ autor afirma, ainda, que tal administração só alcançará seu objetivo se esta se configurar como prática democrática e cooperativa. Dessa forma, torna-se sobremaneira relevante que todos os envolvidos nesse processo, sejam eles diretores, coordenadores, professores, estudantes e comunidade, compreendam as finalidades da educação, realizando um trabalho comprometido com os interesses desse coletivo que constitui a escola pública. Nunca é demais mencionar que os interesses aos quais a escola pública deve atender são os da classe trabalhadora, particularmente a mais empobrecida. São esses sujeitos que têm na escola pública a mais importante, senão a única, instituição que Ihes possibilita o acesso aos conhecimentos historicamente acumulados e sistematizados. Esses conhecimentos poderão oferecer elementos importantes para a compreensão da realidade, para entender a necessidade da transformação social e, principalmente, para a compreensão da imprescindibilidade de querer essa transformação a partir constituição ou adesão de coletivos que tenham o mesmo propósito.

Como quinto e último pressuposto para a gestão democrática da escola pública, Paro (2012) reforça a necessidade de se considerar as condições concretas para o desenvolvimento das ações da escola. $O$ autor defende que uma administração escolar democrática, voltada para atender os interesses da classe trabalhadora, faz parte de um processo complexo e contínuo, que deve levar em consideração as possibilidades reais que a escola tem.

Diante do exposto, podemos não só verificar a complexidade do trabalho daqueles que atuam na gestão escolar, como também perceber a escola como uma instituição que, mesmo sendo composta por órgãos colegiados de gestão, nem sempre encontra entre eles interesses comuns. Dessa forma, também podemos perceber o quão importante é a construção coletiva da proposta pedagógica da escola, materializada em um documento que denominamos de Projeto Político Pedagógico. O documento, ao envolver todos os segmentos da comunidade escolar, estabelece os objetivos comuns que refletem, ou devem refletir, os interesses do público-alvo dessa instituição, a classe trabalhadora.

Compreender que o modelo da administração escolar difere da administração empresarial é o primeiro passo para a transformação da administração escolar. Entretanto, trabalhar cooperativamente com os Órgãos Colegiados de Gestão é uma tarefa nem sempre fácil, necessita da clareza dos objetivos propostos e de uma postura dialógica com todos os segmentos. Este é o desafio a que nos vemos expostas na condição de profissionais que terão em algum momento das trajetórias profissionais a incumbência de materializar essas ações. São questões a serem abordadas na próxima seção. 


\section{CARACTERIZAÇÃO DO CAMPO DE ESTÁGIO}

A Escola de Educação Básica Presidente João Goulart está situada no município de Balneário Camboriú e iniciou suas atividades em 20 de junho de 1963. Uma imersão no Projeto Político Pedagógico da Escola nos permitiu identificar que seu objetivo consiste em realizar "[...] uma ação educativa fundamentada nos princípios de igualdade e democracia, que visa à socialização e o desenvolvimento do/a educando/a, preparando-o/a para o exercício da cidadania, o respeito às diferenças[...]" (EEB PRESIDENTE JOÃO GOULART, 2017, p. 4).

A escola mencionada atendia, no momento da realização do estágio, a 1011 estudantes, assim distribuídos: 155 frequentavam os Anos Iniciais do Ensino Fundamental, 205 os Anos Finais, 534 o Ensino Médio e 117 o curso de Magistério, também de nível médio. A escola funciona nos períodos diurno (manhã e tarde) e noturno.

Dados do PPP (2017) da escola indicam que os estudantes ali matriculados são, em sua maioria, naturais de Santa Catarina. Em relação às etnias, aponta o documento, $93 \%$ se declaram brancos, $5 \%$ mulatos ou negros e $2 \%$ pardos. Ainda de acordo com os dados presentes no PPP, $75 \%$ dos estudantes moram no centro de Balneário Camboriú e apenas 25\% residem nos bairros ou outros municípios.

A equipe gestora é composta por uma diretora e por duas assessoras de direção, todas licenciadas, com pós-graduação lato sensu e quarenta horas semanais de dedicação à escola. A equipe técnica administrativa conta com quatro Orientadoras Educacionais, dois Supervisores Escolares, três Assistentes de Educação e dois Assistentes Técnicos Pedagógicos. O corpo docente é composto por 33 professores efetivos e habilitados para exercer sua função e 35 professores Admitidos em Caráter Temporário (ACTs), totalizando um número de 76 professores. Entre os ACT's, oito não são licenciados (EEB PRESIDENTE JOÃO GOULART, 2017).

\subsection{DOCUMENTOS ORIENTADORES DA GESTÃO ESCOLAR}

O Projeto Político Pedagógico (PPP) da escola, segundo informações da equipe gestora, é revisto anualmente, com a participação de toda a comunidade. $\mathrm{O}$ documento está estruturado em sete capítulos, sendo eles: a) apresentação da Instituição; b) Dimensão Pedagógica que apresenta os eixos norteadores do processo de ensino e aprendizagem, a proposta curricular, informações sobre o planejamento e outros aspectos que estão relacionados aos processos de ensino e aprendizagem. Além disso, este capítulo apresenta a estrutura física da escola, a caracterização dos profissionais que a compõem e as normas institucionais; d) Dimensão Administrativa, que expõe aspectos da organização da gestão, contemplando a identificação servidores (corpo docente, diretora e assessoras de direção, equipe 
pedagógica e administrativa, grêmio estudantil, associação de pais e professores, merendeiras e serviços gerais, entre outros; e) Dimensão Física constitui o quarto capítulo, e refere-se à infraestrutura da escola, a organização do espaço, enfatizando as questões de acessibilidade; f) Dimensão Financeira trata dos recursos financeiros da escola; g) Projetos, Metas e Responsáveis, é o penúltimo capítulo e sistematiza os projetos que a escola desenvolve, tendo como principais parceiros os sujeitos que possuem relação direta com a escola (servidores, estudantes e suas famílias e membros da comunidade) e os Governos Federal e Estadual. Os objetivos a serem alcançados, seja no âmbito pedagógico ou financeiro, e os responsáveis na execução e alcance das tais metas e projetos estão definidos nesta parte do PPP; h) Consolidação do PPP, como último capítulo.

\subsection{MECANISMOS DE GESTÃO DEMOCRÁTICA}

A escolha do(a) diretor(a), na instituição em análise, ocorre por meio da eleição de um Plano de Gestão construído pelo candidato ao cargo em conjunto com a comunidade escolar. De acordo com a diretora, em conversas informais realizadas com a mesma durante a realização do Estágio Supervisionado - Gestão, o Plano de Gestão que a elegeu foi construído com a participação de uma representação da comunidade escolar, por adesão. Vale mencionar, contudo, que, segundo ela, a reformulação desse Plano de Gestão, que ocorreu após sua eleição, contou com uma participação maior da comunidade escolar, por meio de reuniões, conversas com os professores, Grêmio Estudantil, Associação de Pais e Professores e Conselho Deliberativo Escolar.

Como mecanismos de gestão democrática, a escola conta com os seguintes órgãos colegiados de gestão: a Associação de Pais e Professoras, o Grêmio Estudantil e o Conselho Deliberativo Escolar. A Associação de Pais e Professores é composta por pais e professores da escola, como a própria denominação informa. O Grêmio Estudantil é a entidade representativa dos estudantes. Eles devem participar ativamente das questões que envolvem elaboração, execução, avaliação e reelaboração do PPP como meio de favorecer uma prática democrática e o desenvolvimento de uma consciência crítica e reflexiva. O Conselho Deliberativo Escolar é uma das mais "importantes organizações que congregam todos os atores do ato educativo, para a promoção de ações que possibilitem às escolas cumprirem de forma eficaz e eficiente sua função social" (EEB PRESIDENTE JOÃO GOULART, 2017, p. 31).

\section{AVALIAÇÃO INSTITUCIONAL COMO MECANISMO E INSTRUMENTO DE GESTÃO DEMOCRÁTICA}

A escola, espaço de problematização da realidade, tem por finalidade oferecer aos estudantes um ambiente de interação e construção do 
conhecimento, favorecendo a apropriação dos saberes historicamente acumulados. Para acompanhar em que medida tal conhecimento está sendo apropriado pelos estudantes, os professores utilizam-se de diferentes instrumentos de avaliação.

Segundo o dicionário Aurélio (FERREIRA, 1999), avaliar é "determinar ou conhecer o valor de algo". Assim, entendemos que a avaliação não pode se restringir a verificar a aprendizagem dos estudantes, mas deve se estender aos demais âmbitos da escola. Isso quer dizer que, além dos estudantes, os professores, a equipe pedagógica e administrativa, os gestores, os funcionários e até mesmo os pais necessitam ser avaliados e realizar a autoavaliação acerca da sua prática diante do processo educativo. Partindo dessa perspectiva, entendemos que a avaliação institucional pode ser pensada como um mecanismo de gestão democrática por permitir não só identificar os limites e as potencialidades da instituição e dos próprios sujeitos envolvidos no processo educativo, mas também de orientar as ações.

A avaliação se constitui em um processo de busca de compreensão da realidade escolar, com o fim de subsidiar as tomadas de decisões quanto ao direcionamento das intervenções, visando ao aprimoramento do trabalho escolar. Como tal, a avaliação compreende a descrição, a interpretação e o julgamento das ações desenvolvidas, resultando na definição de prioridades a serem implementadas e rumos a serem seguidos, tendo como referências os princípios e as finalidades estabelecidos no Projeto da Escola, ao mesmo tempo em que subsidia a sua própria redefinição. (SOUSA, 1995, p. 63).

Considerado o exposto, entendemos que, ao pensar e instituir um processo de avaliação institucional, cabe aos envolvidos no processo educativo compreender a intencionalidade da mesma, uma vez que, conforme já mencionamos, a avaliação institucional pode servir a diferentes interesses. Portanto, é indispensável:

[...] verificar a serviço de quem está a avaliação: a serviço da regulação, do aumento do controle do estado, do poder coercitivo sobre os professores, sobre a escola, mais fiscalizador. Ou se é um instrumento que permite perceber onde há deficiências e soluções para corrigi-las. Se o objetivo é a aprendizagem do aluno, a melhor modalidade de avaliação é a pública e participativa. Se o objetivo é aumentar o controle do estado sobre o que se faz na escola, a avaliação externa cumpre-o bem. (SOUZA, 2009, p. 21)

A partir das considerações da autora, entendemos a avaliação institucional como um mecanismo que pode ser uma importante ferramenta de coleta de dados que pode contribuir para a reflexão sobre a prática e a ressignificação dos processos educativos. 
Vale mencionar ainda que, além da iniciativa de alguns gestores escolares em realizar avaliação institucional, os governos têm instituído processos em larga escala com propósitos que nem sempre possuem a dimensão defendida neste trabalho: dar voz à comunidade escolar. Vale dizer, ainda, que as avaliações em larga escala, elaboradas e implantadas pelo Governo Federal, iniciaram em 1990, quando o Instituto Nacional de Estudos e Pesquisas Educacionais Anísio Teixeira (INEP) instituiu o SAEB (Sistema de Avaliação da Educação Básica). Nos dias atuais, o SAEB é subdividido em três mecanismos avaliativos: Avaliação Nacional da Alfabetização (ANA), Avaliação Nacional da Educação Básica (Aneb) e Avaliação Nacional do Rendimento Escolar (Anresc), mais conhecida como Prova Brasil. Além dessas, há o Exame Nacional do Ensino Médio e o Sistema Nacional de Avaliação do Ensino Superior.

Apesar desses mecanismos terem potencial para contribuir com a gestão educacional, a publicização da avaliação está restrita ao rendimento acadêmico do estudante. A forma como são utilizados os dados acaba por reforçar a construção de um imaginário de escola pública ineficiente e ineficaz. Não aparece nas análises que a verificação do rendimento escolar é feita a partir de provas que desconsideram o contexto dos estudantes; que são produzidas a partir de recortes de conteúdo; que a maioria das escolas públicas possuem estruturas físicas precárias, com falta de recursos didáticos e pedagógicos para a execução do trabalho docente; que há uma desvalorização da profissão docente, sendo os planos de carreira dos profissionais da educação pouco atrativos; que é necessário melhorar a formação inicial e continuada dos profissionais da educação; que o modelo de gestão predominante ainda se respalda em práticas não participativas e democráticas, ou seja, cujas decisões são ou estão centradas na figura do diretor (em sua grande maioria indicado politicamente para o cargo) ou da equipe gestora da Secretaria de Educação.

Tendo em vista o exposto, qualquer instrumento de avaliação institucional que tenha como princípio servir de mecanismo de gestão democrática deve partir das especificidades da escola e ter como horizonte a oferta da educação de qualidade para os estudantes.

Colocando o foco central da avaliação institucional na sua forma global, no sentido de formação, muito mais do que um simples processo informativo e estabelecendo um caráter educativo, é que será possível se obter um processo avaliativo amplo e penetrante no objetivo de buscar evidenciar o que é preciso mudar e o que é preciso fortalecer e ampliar para a obtenção do sucesso relacionado à qualidade da educação. (POLIDORI; FONSECA; LARROSA, 2007. p. 337).

A partir dessas reflexões, evidencia-se a responsabilidade dos professores, dos gestores e órgãos colegiados de gestão em pensar a avaliação como um instrumento que permita a reflexão sobre a prática de 
todos os envolvidos no processo educativo e de reorientação das ações desses coletivos. Sabemos, contudo, que essa não é tarefa fácil, dada a complexidade das ações relacionadas à administração da escola e das relações socioculturais, políticas e econômicas que se estabelecem dentro e fora do ambiente escolar.

Tendo presentes essas reflexões, a realização do Estágio Supervisionado Gestão, ao demandar e possibilitar reflexões acerca da Avaliação Institucional, permitiu-nos não só uma reflexão teórica acerca da temática, mas também a realização de um exercício prático. Tal exercício se deu a partir da elaboração de instrumentos de avaliação institucional para serem respondidos por estudantes, professores, pais, coordenação pedagógica e coordenação administrativa. Tais instrumentos foram construídos para serem propositivos para os gestores e auto avaliativos aos respondentes e abrangeram questões que pudessem tanto avaliar a gestão da dimensão física, administrativa e pedagógica da escola, como promover a autoavaliação dos respondentes.

\section{CONSIDERAÇÕES FINAIS}

O estágio supervisionado caracteriza-se como um componente curricular importante para a formação em qualquer área de atuação profissional. O Instituto Federal Catarinense - Campus Camboriú, por meio do Estágio Supervisionado - Gestão do curso de Pedagogia vem, ao longo dos anos, construindo uma proposta de estágio que aproxime os estudantes do campo de atuação profissional da gestão.

Durante o tempo de realização do estágio, esta aproximação se deu de diferentes formas, entre as quais mencionamos: o conhecimento dos documentos orientadores da gestão das escolas da Rede Estadual de Ensino de Santa Catarina (Projeto Político Pedagógico e Plano de Gestão); o convívio com a equipe gestora e a possibilidade de acompanhar a rotina de uma instituição de ensino em toda a sua complexidade; o acesso aos dados/informações da escola; o conhecimento das diferentes funções e atribuições da equipe de gestão, principalmente daquelas funções que demandam a mobilização de saberes pedagógicos e envolvem alguma das possibilidades de atuação do pedagogo; a identificação da existência de órgãos colegiados de gestão e de seu papel na gestão da escola em uma perspectiva democrática.

O estágio supervisionado configurou-se, portanto, como uma etapa da formação fundamental, inclusive para a desconstrução e reconstrução de conceitos acerca da gestão escolar e, particularmente, no que diz respeito à avaliação institucional. Dizemos isso considerando que, apesar de ser um dos conteúdos dos componentes curriculares de Gestão Educacional e Gestão Escolar, a imersão na escola e, especialmente, a elaboração de instrumentos de avaliação institucional que podem servir de subsídio para pensar a avaliação institucional da escola de forma coletiva, foi uma experiência que fortaleceu nossa formação e apurou o olhar sobre as possibilidades, mas 
também sobre os limites da avaliação, dependendo do uso que se faz dela. Essa inserção permitiu-nos articular a teoria com a prática, conforme previsto nas Diretrizes Curriculares Nacionais para o Curso de Graduação em Pedagogia, licenciatura.

As reflexões realizadas durante o estágio, o exercício do registro desta experiência em nosso relatório e, particularmente, neste texto, fizeramnos compreender que a implementação de uma gestão verdadeiramente democrática da escola pública ainda está no horizonte. Fez-nos entender, ainda, que a profissão docente traz consigo complexidades que extrapolam o que vivenciamos na formação inicial. Responder pela gestão de uma escola envolve situações muito diversas e adversas, por vezes imprevisíveis.

Por fim, salientamos que a reflexão acerca do que vivemos durante o período de formação inicial, por meio de várias inserções nos diferentes campos de atuação do pedagogo, são fundamentais nesse processo formativo. Essa inserção permite reconhecer a multiplicidade de concepções e culturas presentes nesse campo que são desafiadoras. Elas não só revelam a complexidade do processo educativo, mas nos permitem pensar que existem possibilidades de transformação da realidade. Ainda há possibilidades para que possamos contribuir para a construção de uma sociedade mais justa a partir da ampliação dos espaços de vivência da democracia, que permitam o exercício da cidadania plena. Construir e ocupar esses espaços é uma tarefa urgente. A avaliação institucional pode ser um dos caminhos, se tomada como um instrumento e um mecanismo que favoreça a participação e a decisão coletiva, e, portanto, a materialização da gestão democrática da escola pública comprometida com os interesses dos sujeitos que a frequentam, ou seja, a classe trabalhadora.

\section{REFERÊNCIAS}

BEHRENS, M. A. Formação continuada dos professores e a prática pedagógica. Curitiba: Champagnat, 1996.

BRASIL. Constituição da República Federativa do Brasil. Brasília, 1998. EEB PRESIDENTE JOÃO GOULART. Projeto político Pedagógico. Balneário Camboriú. 2017.

FERREIRA, A. B. H. Novo Aurélio século XXI: dicionário da língua portuguesa. Rio de Janeiro: Nova Fronteira, 1999.

GERHARDT, T. E.; SILVEIRA, D. T. Métodos de pesquisa Porto Alegre:

Editora da UFRGS, 2009. Disponível em:

$<$ http://www.ufrgs.br/cursopgdr/downloadsSerie/derad005.pdf> Acesso em: 11 nov. 2017.

PARO, V. H. Administração Escolar: introdução crítica. São Paulo: Cortez, 2012. 
POLIDORI, M. M.; FONSECA, D. G.; LARROSA, S. F. T. Avaliação

Institucional Participativa. V. 12, n. 2. Jun. 2007, p. 333-348. Disponível em: $<$ http://www.scielo.br/pdf/aval/v12n2/a08v12n2.pdf > Acesso em: 16 out. 2017.

SANTA CATARINA. Decreto no 3.429, de 08 de dezembro de 1998. disponível

in:<http://www.seduc.mt.gov.br/educadores/Documents/Gest\%C3\%A30\%20d e\%20Pessoas/Legisla\%C3\%A7\%C3\%A30\%20Vigente/Decreto n 3.429 de 8 de dezembro de 1998[1].pdf>

SOUSA, S. Z. Avaliação Escolar: constatações e perspectivas. Revista de Educação AEC, Brasília -DF, ano 24,no 94, p.59-66, jan./mar.,1995.

Avaliação Institucional: elementos para discussão. São Paulo, 1999. Disponível em:

$<$ http://moodle3.mec.gov.br/ufmg/file.php/1/gestores/planejamento/pdf/u2 eix o1 1.pdf $>$ Acesso em: 18 set. 2017

SOUZA, L. G. A Avaliação de políticas públicas educacionais: contexto e conceitos em busca da avaliação pública. In.: LORDÊLO, José Albertino Carvalho. DAZZANI, Maria Virgínia. Avaliação educacional: desatando e reatando nós. Salvador: EDUFBA, 2009. 349 p. ISBN 978-85-232-0654-3. Disponível in.: <https://static.scielo.org/scielobooks/wd/pdf/lordelo9788523209315.pdf> Acesso em: 11 nov. 2017. 